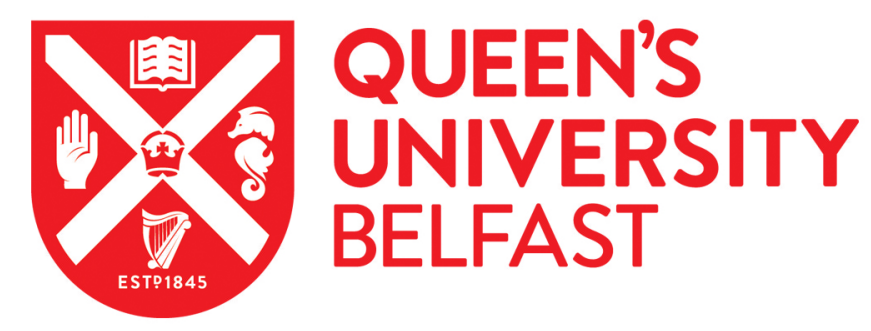

\title{
Hydrophilic divinylbenzene for equilibrium sorption of emerging organic contaminants in aquatic matrices
}

Huysman, S., Vanryckeghem, F., De Paepe, E., Smedes, F., Haughey, S. A., Elliott, C. T., Demeestere, K., \& Vanhaecke, L. (2019). Hydrophilic divinylbenzene for equilibrium sorption of emerging organic contaminants in aquatic matrices. Environmental science \& technology. https://doi.org/10.1021/acs.est.9b01814

Published in:

Environmental science \& technology

Document Version:

Peer reviewed version

Queen's University Belfast - Research Portal:

Link to publication record in Queen's University Belfast Research Portal

Publisher rights

Copyright 2019 ACS. This work is made available online in accordance with the publisher's policies. Please refer to any applicable terms of use of the publisher.

\section{General rights}

Copyright for the publications made accessible via the Queen's University Belfast Research Portal is retained by the author(s) and / or other copyright owners and it is a condition of accessing these publications that users recognise and abide by the legal requirements associated with these rights.

Take down policy

The Research Portal is Queen's institutional repository that provides access to Queen's research output. Every effort has been made to ensure that content in the Research Portal does not infringe any person's rights, or applicable UK laws. If you discover content in the Research Portal that you believe breaches copyright or violates any law, please contact openaccess@qub.ac.uk. 


\section{Hydrophilic divinylbenzene for equilibrium sorption}

of emerging organic contaminants in aquatic

\section{matrices}

\section{KEYWORDS}

17 emerging organic contaminants; hydrophilic DVB; water; equilibrium partitioning; sorption;

18

Steve Huysman ${ }^{\dagger, 1}$, Francis Vanryckeghem ${ }^{\ddagger 1}$, Ellen De Paepe ${ }^{\dagger}$, Foppe Smedes $^{\S}$, Simon A. Haughey", Christopher T. Elliott", Kristof Demeestere ${ }^{\ddagger, 2}$ and Lynn Vanhaecke ${ }^{*,+, \|, 2}$

${ }^{\dagger}$ Ghent University, Faculty of Veterinary Medicine, Department of Veterinary Public Health and Food Safety, Laboratory of Chemical Analysis (LCA), Merelbeke, Belgium;

$\$$ Ghent University, Faculty of Bioscience Engineering, Department of Green Chemistry and Technology, Research Group Environmental Organic Chemistry and Technology (EnVOC), Ghent, Belgium;

${ }^{\S}$ Masaryk University, Faculty of sciences, Research Centre for Toxic Compounds in the Environment, Brno, Czech Republic;

" Queen's University, Institute for Global Food Security, School of Biological Sciences, Belfast, Northern Ireland.

\section{sampling}


Hydrophilic divinylbenzene (DVB) (Bakerbond $^{\mathrm{TM}}$ ) has surfaced as a promising sorbent for

21 active sampling of analytes from aqueous matrices over a very broad polarity range. Given this,

hydrophilic DVB may likewise offer potential for passive sampling, if sorbent-water partitioning coefficients $\left(\mathrm{K}_{\mathrm{sw}}\right)$ were to be available. In this work, static exposure batch experiments were performed to quantitatively study the equilibrium sorption of 131 environmentally relevant organic contaminants (P values ranging from -1.30 to 9.85) on hydrophilic DVB. The superior affinity of hydrophilic DVB, as compared to Oasis HLB, for compounds with a broad polarity range was confirmed by functional FTIR and Raman characterization, demonstrating the presence of carboxyl moieties. Concentration effects were studied by increasing compound concentrations in mixture experiments, and resulted for the steroidal EDCs in higher $\mathrm{K}_{\mathrm{sw}}$, while lower $\mathrm{K}_{\mathrm{sw}}$ were obtained for the (alkyl)phenols, personal care products, pesticides, pharmaceuticals and phthalates. Nevertheless, $\mathrm{K}_{\mathrm{sw}}$ remained constant in said design for equilibrium water concentrations at environmentally relevant seawater levels. Independent analysis of thermodynamic parameters (change in enthalpy, entropy and Gibbs free energy) revealed the nature of the main partitioning processes. While polar $(\log \mathrm{P}<4)$ compounds were mainly served by physisorption, non-polar $(\log \mathrm{P}>4)$ compounds also exhibited binding by multiple hydrogen bonding. In conclusion, this research facilitates the future application of hydrophilic DVB for active as well as passive sampling in the analysis of organic contaminants for monitoring purposes but also for toxicity testing. 
The ever-increasing number of emerging contaminants released into our (aquatic) environment stresses the need for the deployment of efficient monitoring strategies ${ }^{1}$. In this context, the use of polymeric sorbents has surfaced as a highly valuable strategy for active and passive sampling of organic compounds from aquatic matrices ${ }^{2,3}$. In active sampling, polymeric sorbents are widely used in solid-phase extraction (SPE) cartridges for the enrichment of contaminants and/or cleanup of aquatic matrices ${ }^{2}$. In recent years, however, the number of publications on the application of polymeric sorbents and materials in passive sampling studies is steadily increasing.

At present, a number of polymeric materials have been applied for the monitoring of emerging contaminants using passive sampling based approaches ${ }^{3,4}$. However, most studies focus on specific polymeric passive samplers efficiently binding compounds within a specific polarity range ${ }^{5}$. In passive sampling, the function of a sampler as an infinite sink is determined by the affinity towards the envisaged analytes, which is governed by the polarity, (inversely related to $\log \mathrm{P}$ ) and chemical functionalities of both. Indeed, silicones (mainly polydimethylsiloxane, PDMS) invoke the uptake of non-polar chemicals $(\log \mathrm{P}>4)^{6,7}$, while Chemcatchers ${ }^{\circledR}$ SDB-RPS (sulfonated divinylbenzene - reversed phase sulfonate) mainly accumulate more polar chemicals $(\log \mathrm{P}<4)$ and Chemcatchers ${ }^{\circledR} \mathrm{C}_{18}$ sample compounds ranging from moderately polar to moderately nonpolar, i.e. $\log \mathrm{P}$ ranging between 0.9 and $5.8^{8,9}$. In this context, the Oasis $\mathrm{HLB}^{\circledR}$ co-polymer has gained in popularity and was recently incorporated in different POCIS configurations ${ }^{10,11}$, as it permits the accumulation of very polar to moderately non-polar compounds (log P ranging from 1.6 up to 5$)^{12}$. Its affinity towards hydrophobic compounds $(\log \mathrm{P}>5)$ however still remains a hurdle ${ }^{5}$. In this work, we propose hydrophilic DVB as a sorbent for sampling a broad range of emerging contaminants. Although hydrophilic modified DVB materials have been applied earlier as solid phase microextraction fibers, blades and membranes ${ }^{13-15}$, the potential of hydrophilic 
DVB for passive sampling of such a broad range of emerging contaminants remains underexplored as opposed to the frequently applied Oasis $\mathrm{HLB}^{\circledR}$ sorbent. Moreover, higher extraction efficiencies were obtained using hydrophilic DVB for non-polar compounds ( $\log \mathrm{P}>4)$ during active sampling as compared to Oasis $\mathrm{HLB}^{\circledR}{ }^{16}$. Hence, investigating the underlying mechanisms of said hydrophilic DVB sorbent in both active (SPE) and passive sampling seems promising. Indeed, there is no information available on the surface chemistry (functional groups, pore size and particle size distribution) of hydrophilic DVB neither on the partitioning behaviour of organic contaminants between water and hydrophilic DVB ${ }^{17}$. Furthermore, hydrophilic DVB is commercially available in a robust housing, i.e. Bakerbond Speedisks ${ }^{\circledR}$, which simplifies its application for passive sampling of the aquatic environment.

Therefore, the goal of this work was to investigate the equilibrium sorption behaviour of a broad range of aqueous organic contaminants on freely dispersed hydrophilic DVB sorbent. The specific objectives included (i) revealing the surface chemistry of hydrophilic DVB, (ii) determining the $\mathrm{K}_{\mathrm{sw}}$ of a mixture of 131 environmentally relevant organic contaminants at field concentrations, (iii) examining sorption linearity of the target organic contaminants by increasing compound concentrations, and (iv) assessing the impact of relevant environmental parameters (i.e. temperature, $\mathrm{pH}$ and salinity) on $\mathrm{K}_{\mathrm{sw}}$. Ultimately, this research intends to reveal the underlying mechanisms of hydrophilic DVB sorption in active and passive sampling.

\section{MATERIALS AND METHODS}

Chemicals and materials. In this study, standards of 131 environmentally relevant organic contaminants (log P ranging from -1.30 to 9.85 , depicted in Table S1) were purchased at Bayer (Germany), Fluka (Belgium), Sigma Aldrich (St. Louis, MO, USA), Steraloids Inc (Newport, RI, 
USA), Lipomed GmbH (Germany), MpBio (Belgium) and TRC (Canada), covering 6 major classes, i.e. 4 alkylphenols, 5 personal care products, 25 pesticides, 32 pharmaceuticals, 15 phthalates and 50 steroidal endocrine disrupting compounds (EDCs). The selected organic contaminants were based on legislative frameworks and directives for protecting surface and marine waters, i.e. the U.S. Clean Water Act, the EU WFD watchlist, OSPAR, Reach and Norman ${ }^{18-22}$. Primary stock solutions and standard mixtures were prepared in pure methanol $\left(\mathrm{CH}_{3} \mathrm{OH}\right)$ or in a mixture of methanol/water (10/90, v/v \%) with $0.1 \%(\mathrm{v} / \mathrm{v} \%)$ formic acid and $0.1 \mathrm{~g} \mathrm{~L}^{-1}$ $\mathrm{Na}_{2}$ EDTA. $2 \mathrm{H}_{2} \mathrm{O}$, the latter only for pesticides, pharmaceuticals and personal care products, thereby attaining concentrations between 0.01 and $1000 \mathrm{ng} \mu \mathrm{L}^{-1}$. Solutions were stored in dark glass bottles at $-20^{\circ} \mathrm{C}$. Organic solvents were of Optima UPLC-MS grade, purchased from Fisher Scientific (Loughborough, UK). The inorganic salts, used to prepare reference seawater, were supplied by Sigma Aldrich (St. Louis, MO, USA) and processed according to ASTM D-1141 23 . The hydrophilic divinylbenzene (DVB) Speedisks ${ }^{\circledR}$ and Oasis ${ }^{\circledR}$ HLB cartridges (200 and $500 \mathrm{mg}$ ) were purchased from Filterservice (Eupen, Belgium) and Waters (Brussels, Belgium), respectively.

Static exposure batch experiments. A classic static exposure batch system, which has previously been applied for passive sampling studies ${ }^{24,25}$, was established under controlled conditions of continuous stirring (100 rpm), temperature (experiment dependent) and absence of light. The latter was applied to determine the $\mathrm{K}_{\mathrm{sw}}$ of a mixture of the 131 selected contaminants between artificial seawater and the hydrophilic DVB sorbent. It was also studied how compound concentration and environmental parameters affect the $\mathrm{K}_{\mathrm{sw}}$-values. Aqueous suspensions, containing $25 \mathrm{mg}$ of freely dispersed hydrophilic DVB sorbent $\mathrm{L}^{-1}$ were used in all batch experiments. The DVB sorbent has a pore size of $200 \AA$ and a particle size between 12 and $42 \mu \mathrm{m}$ 
110 (for $95 \%$ of the particles) as demonstrated in Figure S1. The sorbent/water-ratio was determined

111 based on preliminary experiments. A higher sorbent/water-ratio disabled us to quantify the spiked

112 compounds, as aqueous equilibrium concentrations were below the analytical detection limits.

113 Compound mixtures were spiked in $1 \mathrm{~L}$ glass beakers closed with aluminium foil ${ }^{26}$ to prevent

114 evaporation. At the end of each batch test, the beaker's content, containing both the aqueous and

115 sorbent phases, was filtered over a Whatman GF/D glass fibre filter coupled in series with a packed

116 SPE cartridge to extract the analytes from the aqueous phase (see supplementary information,

117 Figure S 2). The glass fibre filter with sorbent phase and packed SPE cartridge were separately

118 eluted and analysed, to provide sorbent and aqueous concentrations, respectively. The subsequent

119 sample preparation and analysis were optimised for the different compound groups of interest (see

120 sample analysis). Furthermore, to evaluate potential adsorption to glass walls and/or hydrolysis of

121 the spiked compounds during batch experiments, reference glass beakers were included in the

122 experimental set-up. These reference glass beakers, containing only water at the initial nominal

123 concentrations of the selected compounds and no sorbent, were subjected to similar conditions as

124 beakers containing the spiked compounds with sorbent. In addition, blank samples were also

125 examined and used for adjusting $\mathrm{K}_{\mathrm{sw}}$.

126 Experimental determination of $\mathbf{K}_{\mathbf{s w}}$. The $\mathrm{K}_{\mathrm{sw}}$ were determined at neutral $\mathrm{pH}$ conditions and at

127 a temperature of $8^{\circ} \mathrm{C}$. The spike concentration for the target compounds was based on

128 environmentally relevant levels but sufficiently high as to enable measurements above the

129 methods' detection limits after sorbent sorption. As such, the initial nominal concentration was set

130 at $1.5 \mathrm{nmol} \mathrm{L}^{-1}$ for each compound. The residual concentrations in water and the amounts

131 accumulated by the sorbent were measured at $0,1,2,4,6,8,12,24,48,96$ and $168 \mathrm{~h}$. These 
experimental times were selected to evaluate whether equilibrium was reached within one day or one week.

Partitioning at different compound concentrations. To investigate the effect of compound concentration on the $\mathrm{K}_{\mathrm{sw}}$, at a contact time of $48 \mathrm{~h}$, multiple equilibrations were performed under similar conditions at various concentration levels, i.e. $0.75,1.5,3.0,6.0,12,24$ and $48 \mathrm{nmol} \mathrm{L}^{-1}$. This experiment was executed at a water temperature of $8^{\circ} \mathrm{C}$ and under neutral $\mathrm{pH}$ conditions.

Partitioning under different environmental conditions. To evaluate the impact of varying environmental conditions on the $\mathrm{K}_{\mathrm{sw}}(48 \mathrm{~h}$ contact time), three parameters were investigated within environmental relevant ranges, i.e. $\mathrm{pH}$, temperature and salinity respectively ranging from 5 to 8 , from 4 to $16^{\circ} \mathrm{C}$, and from 0 to 35 psu. Response surface modelling (RSM), and more specifically the Box-Behnken experimental design, enabled to fit quadratic models to the experimental log $\mathrm{K}_{\mathrm{sw}}$, which contained main, quadratic and interaction factors related to the selected environmental parameters.

Analytical methods. Sorbent characterization. Sorbent characterization was performed to reveal the chemical properties of the hydrophilic DVB surface and to compare the latter with the frequently used Oasis $\mathrm{HLB}^{\circledR}$. This was achieved by the use of a Thermo Scientific Nicolet iS50 spectrophotometer (Thermo Fisher Sicentific, Dublin, Ireland) to obtain the FTIR (Fourier transform infrared), Raman and NIR (Near-infrared) spectra within the range of $400-4000 \mathrm{~cm}^{-1}$, $400-4000 \mathrm{~cm}^{-1}$ and $3000-12000 \mathrm{~cm}^{-1}$, respectively. Other acquisition parameters were: number of scans: 256, number of background scans: 256, background gain: 4.0, and resolution: 4.0 (FTIR and NIR) / 8.0 (Raman). Acquisition was repeated 3 times, and spectral data were averaged prior to further data processing. 

performed using three in-house developed and validated analytical methods, consisting of the appropriate extraction followed by an optimized UHPLC-HR-Q-Orbitrap ${ }^{\mathrm{TM}}$-MS methodology. Chromatographic separation was achieved using reversed phase chromatography with gradient elution using a Hypersil Gold column $(1.9 \mu \mathrm{m}, 50 / 100$ x $2.1 \mathrm{~mm})$. Analyte detection was carried out on a Q-Exactive ${ }^{\mathrm{TM}}$ benchtop HRMS (Thermo Fisher Scientific, San-Francisco, USA). Details regarding the sample analysis have been published earlier ${ }^{16,26,27}$, and only the main differences are briefly described in the supplementary information. In short, the residual water concentrations for the steroidal EDCs were determined by extracting with Bakerbond Hydrophilic DVB

163 Speedisks, while the personal care products, pesticides, pharmaceuticals, (alkyl)phenols and 164 phthalates were extracted by using Oasis ${ }^{\circledR} H L B$. These analytical methods exhibited excellent 165 performance; i.e. repeatability and precision below $20 \%$ RSD, relative recovery between $80-120$ $166 \%$, and good linearity $\left(\mathrm{R}^{2}>0.99\right.$ and no lack-of-fit).

167 Data treatment and analysis. Spectroscopic data were extracted from the FTIR, Raman and NIR using TQ Analyst 8.6.12 (Thermo Fisher Scientific, Dublin, Ireland). Targeted processing of full-scan data, obtained by the Q-Exactive HRMS, including the identification and quantification 170 of target compounds, was executed by XCalibur ${ }^{\mathrm{TM}} 4.0$ software (Thermo Fisher Scientific). The 171 software program JMP 12.0 (SAS Institute Inc, Cary, USA) was used to evaluate and model the 172 appropriate RSM design Box-Behnken Design. Graphics were produced by using R (Version 3.4).

173 Determination of $K_{s w} . K_{\text {sw }}$ was determined using the above-described static exposure design and

174 calculated by eq 1 , i.e. absolute mass concentration measured in the water $\left(\mathrm{N}_{\mathrm{w}}\right.$; nmol) phase at 175 start conditions $(\mathrm{t}=0)$ and equilibrium ( $\mathrm{t}=$ equilibrium), concentration measured in the water phase 176 at equilibrium $\left(\mathrm{Cw}, \mathrm{t}=\right.$ equilibrium; $\left.\mathrm{nmol} \mathrm{L}^{-1}\right)$ and the amount of sorbent $\left(\mathrm{M}_{\mathrm{s}} ; \mathrm{kg}\right) .{ }^{28}$ 
178 Adsorption modelling. Adsorption isotherms were investigated by applying the Freundlich 179 model (see Eq. 2) ${ }^{29}$, where $\mathrm{qe}_{\mathrm{e}}\left(\mathrm{nmol} \mathrm{g}{ }_{\mathrm{s}}{ }^{-1}\right)$ is the mass of accumulated compound by the sorbent at 180 equilibrium, which equals $\mathrm{C}_{\mathrm{s}, \mathrm{t}}$ as described under 2.4.1, $\mathrm{K}_{\mathrm{F}}\left(\left(\mathrm{nmol} \mathrm{g}_{\mathrm{s}}{ }^{-1}\right) /\left(\mathrm{nmol} \mathrm{L}^{-1}\right)^{\mathrm{n}}\right)$ the Freundlich 181 constant, $\mathrm{C}_{\mathrm{e}}\left(\mathrm{nmol} \mathrm{L}{ }^{-1}\right)$ the compound concentration in the water phase at equilibrium, equivalent 182 to $\mathrm{C}_{\mathrm{w}, \mathrm{t}}$ described under 2.4.2, and $\mathrm{n}$ the dimensionless Freundlich exponent. The thermodynamic 183 parameters ${ }^{29}$, i.e. change in Gibbs free energy $\left(\Delta \mathrm{G}_{288,15 \mathrm{~K}}\right)$, enthalpy $(\Delta \mathrm{H})$ and entropy $(\Delta \mathrm{S})$, were

184 determined using the van't Hoff (see Eq. 3) and change in Gibbs free energy equations (see Eq. 185 4). $\mathrm{R}$ represents the universal gas constant $\left(8.314 \mathrm{~J} \mathrm{~K}^{-1} \mathrm{~mol}^{-1}\right)$ and $\mathrm{T}$ the absolute temperature $(\mathrm{K})$.

$186 q_{e}=K_{F} C_{e}^{n}$

$187 \ln \left(K^{\circ}\right)=-\frac{\Delta H^{\circ}}{R T}+\frac{\Delta S^{\circ}}{R}$

Sorbent characterization. To the best of our knowledge, the surface chemistry of hydrophilic 192 DVB has not been studied earlier. This work relied on spectral analysis (i.e. FTIR, Raman and 193 NIR) to unravel surface functionalities of hydrophilic DVB. Additionally, the co-polymer 194 poly(divinylbenzene-co-N-vinylpyrrolidone), also more familiar under the tradename Oasis ${ }^{\circledR}$ 195 HLB, was analysed for comparison. FTIR and Raman spectra are presented in Figure 1, whilst NIR spectra can be found in supplementary Figure S3. 

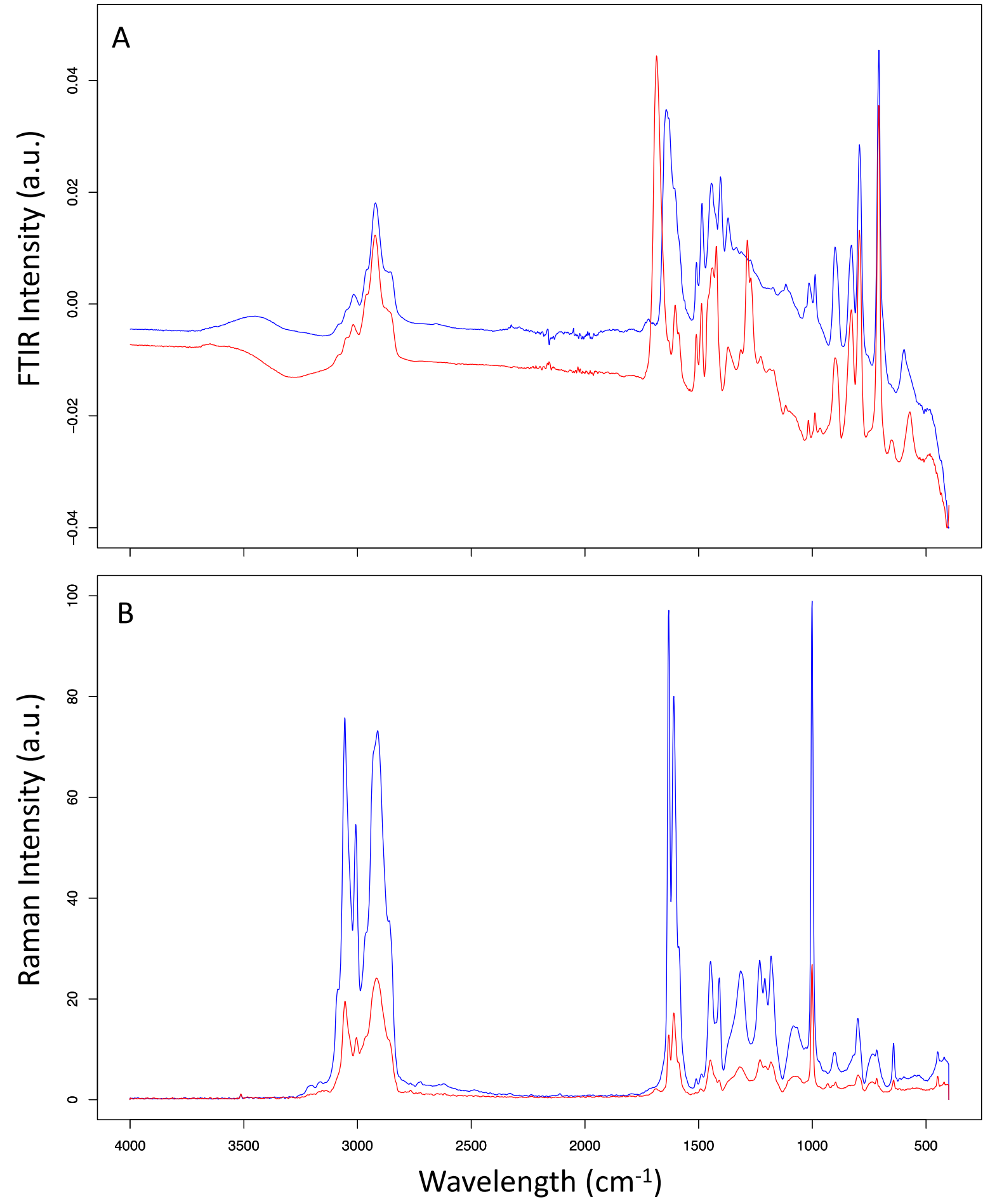

197

198 Figure 1. Averaged FTIR (A, $n=3$ for each sorbent) and Raman (B, $n=3$ for each sorbent)

199 spectroscopic analysis of hydrophilic DVB (Bakerbond ${ }^{\mathrm{TM}}$ ) (Blue) and Oasis ${ }^{\circledR}$ HLB (red). 
Multivariate statistical analysis of the obtained FTIR spectra demonstrated significant 201 differences between the two sorbents ( $\mathrm{p}$-value $<0.05, \mathrm{R}^{2}(\mathrm{X})(\mathrm{cum})=0.989, \mathrm{R}^{2}(\mathrm{Y})=0.99, \mathrm{Q}^{2}(\mathrm{cum})$ $202=0.974)$. The main spectral differences consisted of FTIR peaks at 1642 and $1403 \mathrm{~cm}^{-1}$ for 203 hydrophilic DVB, and $1684 \mathrm{~cm}^{-1}$ for Oasis ${ }^{\circledR}$ HLB. An FTIR peak at $1642 \mathrm{~cm}^{-1}$ has been related to 204 the presence of water adsorbed to amorphous regions of a polymer ${ }^{30,31}$, suggesting the presence 205 of hydroxyl [-OH] and/or ketone [-C=O] groups. The FTIR peak at $1403 \mathrm{~cm}^{-1}$ of hydrophilic DVB 206 represents the presence of carboxyl [-COOH] groups ${ }^{32,33}$. For Oasis ${ }^{\circledR}$ HLB, the FTIR peak at 1684 $207 \mathrm{~cm}^{-1}$ corresponds to the amide $[\mathrm{C}-\mathrm{N}]$ stretching vibration of the pyrrolidine ring present in the PVP 208 (poly-N-vinylpyrrolidone) moiety. As no additional peak was observed at $3400 \mathrm{~cm}^{-1}$ and because 209 the FTIR amide peak was observed within the $1650-1750 \mathrm{~cm}^{-1}$ range, the presence of a tertiary 210 amide was concluded. In addition, for both sorbents, peaks at 1600 and $1510 \mathrm{~cm}^{-1}$ confirmed the 211 occurrence of aromatic hydrocarbons $[\mathrm{C}=\mathrm{C}]$ belonging to the divinylbenzene co-polymer. 212 Complementary to the FTIR spectra, the Raman spectra also provided qualitative and quantitative 213 information on the functional groups of the two sorbents (Figure 1). Raman analysis revealed and 214 confirmed the presence of carboxyl $[-\mathrm{COOH}]$ moieties in the hydrophilic DVB co-polymer, i.e. a 215 peak at $1409 \mathrm{~cm}^{-1}$ was observed ${ }^{34}$. In addition, the occurrence of the Oasis HLB ${ }^{\circledR}$ vinyl-groups $216\left[\mathrm{CH}_{2}=\mathrm{CH}_{2}\right]$ was confirmed as we observed a Raman peak at $1229 \mathrm{~cm}^{-1}$. Aside from the Raman 217 peaks at $1409 \mathrm{~cm}^{-1}$ and $1229 \mathrm{~cm}^{-1}$, in general, similar spectra were observed for both the 218 hydrophilic DVB and Oasis ${ }^{\circledR}$ HLB co-polymers. However, more intense signals were marked for 219 the hydrophilic DVB functional groups, revealing a higher degree of cross-linkage and 220 functionalisation for hydrophilic DVB as compared to Oasis ${ }^{\circledR}$ HLB, offering an explanation for 221 the higher extraction efficiencies for steroidal EDCs, pharmaceuticals, pesticides and personal care 222 products that have generally been observed for hydrophilic DVB versus Oasis ${ }^{\circledR}$ HLB ${ }^{16,27}$. No 
significant ( $p$-value $<0.05$ ) differences were observed between the NIR spectra of hydrophilic DVB and Oasis ${ }^{\circledR}$ HLB.

Equilibrium partitioning between water and hydrophilic DVB. Mass balances. The applied analytical methods for the quantification of the 131 organic contamiants studied in this work, have been extensively and successfully validated as reported earlier ${ }^{16,26,27}$. To assure that decreasing contaminant concentrations measured in the aqueous phase during the aforementioned batch tests were merely caused by sorption on the sorbent, mass balances were calculated for every contaminant. This was achieved by comparing the initially spiked contaminant quantity to the sum 231 of the fractions remaining in the water and sorbent phases ${ }^{35}$. Average mass balances (\%) and 232 corresponding analytical repeatabilities (\% RSD) of the different time points in equilibrium 233 (constant $\mathrm{K}_{\mathrm{sw}}$ ) for each studied contaminant are listed in Table S 1. For the (alkyl)phenols, personal 234 care products, pesticides, pharmaceuticals, phthalates and steroidal EDCs, averaged class-specific mass balances equaled $79 \pm 4 \%, 72 \pm 7 \%, 92 \pm 4 \%, 86 \pm 4,82 \pm 2 \%$ and $75 \pm 4 \%$, while averaged classspecific repeatability was calculated to $5 \%, 11 \%, 4 \%, 8 \%, 2 \%$ and $5 \%$, respectively. As repeatabilities were well below $20 \%$, it may be concluded that batch sorption experiments were consistent and reproducible. Indeed, good to excellent mass balances were obtained for the majority of compounds. Consequently, and because the applied analytical methods were optimised and validated for aqueous matrices, it was decided to calculate the $\mathrm{K}_{\text {sw }}$ solely on water phase concentrations. The remaining losses that were experienced to a certain extent for all compounds were $<25 \%$ after $168 \mathrm{~h}$ and may be assigned to adsorption to glass walls and/or hydrolysis as was reported by Jeong et al. (2017) ${ }^{36}$ as well.

244 Determination of the $K_{s w}$. All organic contaminants studied in this work reached sorption 245 equilibrium between 12 and $24 \mathrm{~h}$. The calculated log transformed $\mathrm{K}_{\mathrm{sw}}$ are listed for the individual 
components in Table S 2, and are depicted per class of compounds in Figure 2. $\mathrm{K}_{\mathrm{sw}}$ ranged over more than 3 orders of magnitude, from $\log \mathrm{K}_{\mathrm{sw}} 4.00$ for nalidixic acid (pharmaceutical) to 7.22 for terbuthylazine (pesticide).

249 To the best of the author's knowledge, only one study of Jeong et al. (2017) determined the sorption of 28 organic compounds to naked SPE sorbent (i.e. Oasis ${ }^{\mathrm{TM}}$ HLB) in a static exposure design. The $\log \mathrm{K}_{\mathrm{sw}}$-values of specific compounds obtained in this study, i.e. metoprolol (5.65), isoproturon (6.44), carbamazepine (6.44), flufenacetate (6.16), diuron (6.81), atrazine (6.33), sulfamethoxazole (4.17), simazine (6.24) and terbutryn (6.42) are comparable (except for sulfamethoxazole) or slightly higher (log $\mathrm{K}_{\mathrm{sw}}$-difference ranged between 0.41 and $1.55 \log$ unit), than those reported by Jeong et al. $(2017)(5.15 ; 6.03 ; 5.64 ; 5.23 ; 5.26 ; 5.29 ; 4.44 ; 5.35$ and 5.39 , respectively). These data suggest that the investigated polar compounds $(\log \mathrm{P}<4)$ have a slightly higher sorption tendency (higher $\mathrm{K}_{\mathrm{sw}}$ values, availability of more divinylbenzene groups (see characterization)) to hydrophilic DVB as compared to the Oasis ${ }^{\mathrm{TM}}$ HLB sorbent. This agrees with the functional characterization data, which demonstrated that hydrophilic DVB comprises hydrophilic moieties with a higher polarity as does Oasis ${ }^{\circledR}$ HLB (see characterization), i.e. carboxyl [-COOH] as opposed to N-vinylpyrrolidone groups.

262 Comparing hydrophilic DVB to other SPE-based sampling devices (with sorbent casing) also corroborates the conclusion that hydrophilic DVB covers a much broader polarity range (log P ranging from -1.30 to 9.85 ) than any previously tested sorbent. Ahrens et al. (2015) tested a broad spectrum of organic compounds with $\log \mathrm{P}$ values ranging from -1.7 to 6.9 , and this for 5 different polymer-based passive sampling devices, to conclude that the sorption of organic compounds to each device was optimal within a specific polarity range. Silicone rubbers, Chemcatcher SDB- 
270 Connol et al. investigated silicone wristbands and found that 49 compounds were sequestered 271 during ambient deployment, encompassing a diverse set of compounds including polycyclic 272 aromatic hydrocarbons, consumer products, personal care products, pesticides, phthalates, and 273 other industrial compounds ranging in $\log \mathrm{K}_{\mathrm{ow}}$ from -0.07 (caffeine) to 9.49 (tris(2-ethylhexyl) 274 phosphate) ${ }^{37}$. Since the above-mentioned study of Ahrens used different types of limiting 275 membranes, $\mathrm{K}_{\mathrm{sw}}$ cannot be compared to our work. Comparing our results with the study of Ahrens 276 et al. (2015), also confirms that hydrophilic DVB is a more functionalised polymer and as such 277 enables the sorption of more hydrophobic compounds than Oasis ${ }^{\mathrm{TM}}$ HLB.

278 In line with the ever-increasing number of chemicals that is released into the environment ${ }^{1}$, 279 several passive sampling-based studies have attempted to mathematically model $\log \mathrm{K}_{\text {sw }}$ using 280 various physico-chemical properties of the compounds under investigation as input ${ }^{7,38-40}$. Up until 281 now, $\log \mathrm{P}$ and molecular weight (MW) have been correlated frequently to the $\log \mathrm{K}_{\mathrm{sw}}\left(\mathrm{r}^{2}=0.92\right.$, $282 \mathrm{n}=65)^{7,38,39}$ for more non-polar compounds $(\log \mathrm{P}>4)$. However, using our complete dataset, 283 lack-of-fit (p-value < 0.05) between $\log$ P or MW and $\log \mathrm{K}_{\text {sw }}$ was observed. Smedes et al. (2018) 284 observed similar findings for the PAHs (polycyclic aromatic hydrocarbons), PCBs 285 (polychlorinated biphenyls) and phthalates ${ }^{41}$. Therefore, we evaluated the modelling potential of 286 a number of other physico-chemical properties, including $\mathrm{V}_{\mathrm{x}}$ (molecular volume), $\mathrm{qA}^{-}$(most 287 negative charge on $\mathrm{O}, \mathrm{N}, \mathrm{S}, \mathrm{X}$ atoms), $\mathrm{H}_{\mathrm{y}}$ (hydrophilic factor), vapor pressure, bioconcentration 288 factor, number of carbon atoms, pKa, water solubility and polar surface area. No valid model $289\left(\mathrm{R}^{2}{ }_{\mathrm{adj}}=0.33, \mathrm{n}=115\right.$, all compounds for which described physico-chemical parameters were 290 available) was however obtained for predicting $\log \mathrm{K}_{\mathrm{sw}}$ with any of the above-mentioned 291 parameters or combinations thereof using the complete dataset. Additionally, it should be 
highlighted that no quantitative effect of type and number of functional groups on the $\mathrm{K}_{\mathrm{sw}}$ was observed (see Figure S4). The above-mentioned results lead to conclude that the partitioning of analytes towards hydrophilic DVB seems to be compound-specific and warrants individual practical determination. The latter is exemplified by the observation that even enantiomers resulted in different $\log \mathrm{K}_{\mathrm{sw}}$, i.e. 6.92 was observed for $17 \alpha$ - while 5.39 was determined for $17 \beta$ testosterone. A similar phenomenon has also been observed during chromatographic separation of analytes, demonstrating different affinities to stationary phases (resulting in different retention times of e.g. testosterone, trenbolone, zearalenol and zeranol) ${ }^{16}$.

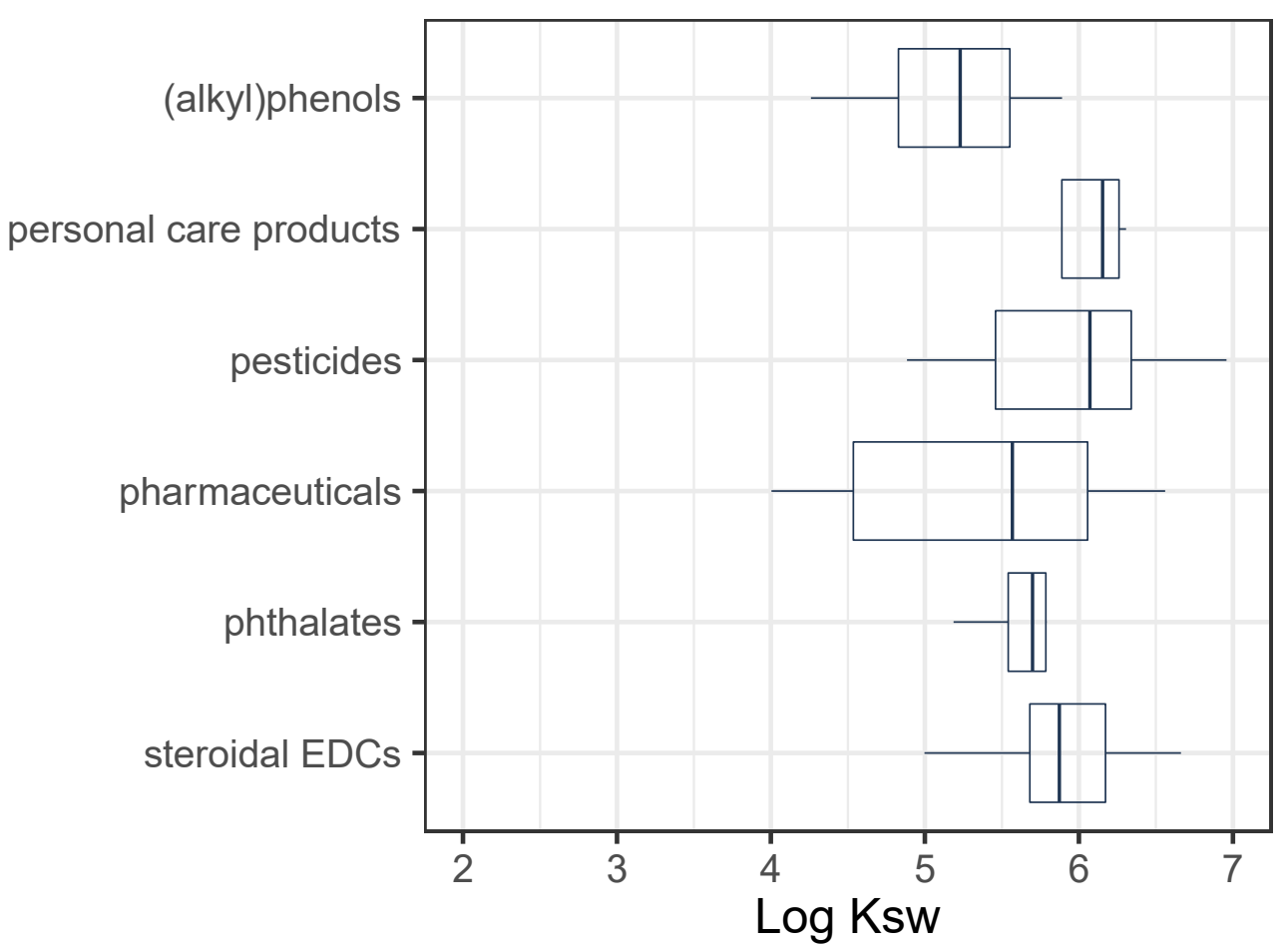

302 Figure 2. The calculated sorbent-water equilibrium partitioning coefficients $\left(\log \mathrm{K}_{\mathrm{sw}}\right)$ of the 303 different classes, i.e. alkylphenols $(n=4)$, personal care products $(n=5)$, pesticides $(n=25)$, 304 pharmaceuticals $(n=32)$, phthalates $(n=15)$ and steroidal EDCs $(n=50)$. The batch systems were 305 kept at a constant temperature of $8^{\circ} \mathrm{C}, \mathrm{pH}$ of 7 and salinity of $35 \mathrm{psu}$. We refer to SI Table 3 for 
individual calculated sorbent-water equilibrium partitioning coefficients $\left(\log \mathrm{K}_{\mathrm{sw}}\right)$ with corresponding standard deviations (SD).

Do increasing organic contaminant concentrations affect $K_{s w}$ ? The influence of dissolved organic contaminant concentrations on their partitioning between artificial seawater and 311 hydrophilic DVB was investigated by varying compound concentrations while keeping the amount 312 of sorbent constant, as depicted for a selection of compounds in Figure 3. Changes in partitioning 313 and surface heterogeneity (reflected by the Freundlich exponent, $n$ ) were assessed by calculating 314 the $\mathrm{K}_{\mathrm{sw}}$ (Eq. 1) and Freundlich isotherms (Eq. 2) respectively (Table S 3). For the steroidal EDCs, 315 higher dissolved concentrations resulted in increased $K_{s w}(n>1)$, showing that higher initial 316 steroidal EDC concentrations tend to enhance sorption capacity. This phenomenon has also been 317 reported for methylene blue and phenol ${ }^{42-45}$, bearing a similar cyclic aromatic structure as do the 318 steroidal EDCs. For the (alkyl)phenols, personal care products, pesticides, pharmaceuticals and 319 phthalates, dissolved concentrations exceeding the linear ranges of the isotherms resulted for 95\% 320 of the 131 studied compounds in reduced $\mathrm{K}_{\mathrm{sw}}(\mathrm{n}<1)$. The latter indicates that partitioning for these 321 groups of organic contaminant depends merely on the available hydrophilic DVB sorption sites. 322 The aforementioned findings stress the need to examine the linear range of the partitioning 323 isotherms for the different organic contaminants. For more than $75 \%$ of the steroidal EDCs $(n>1)$ 324 and all the other classes of studied organic contaminants $(n<1)$, linear isotherms were observed 325 when $\mathrm{C}_{\mathrm{e}}$ was, respectively, lower than $8.5 \mathrm{ng} \mathrm{L}^{-1}$ and $70 \mathrm{ng} \mathrm{L}^{-1}$. The $\mathrm{C}_{\mathrm{e}}$-levels applied in our 326 experimental set-up are in the same order of magnitude than seawater concentrations recently 327 measured in the Belgian Part of the North Sea for the contaminants studied 16,26,27. 

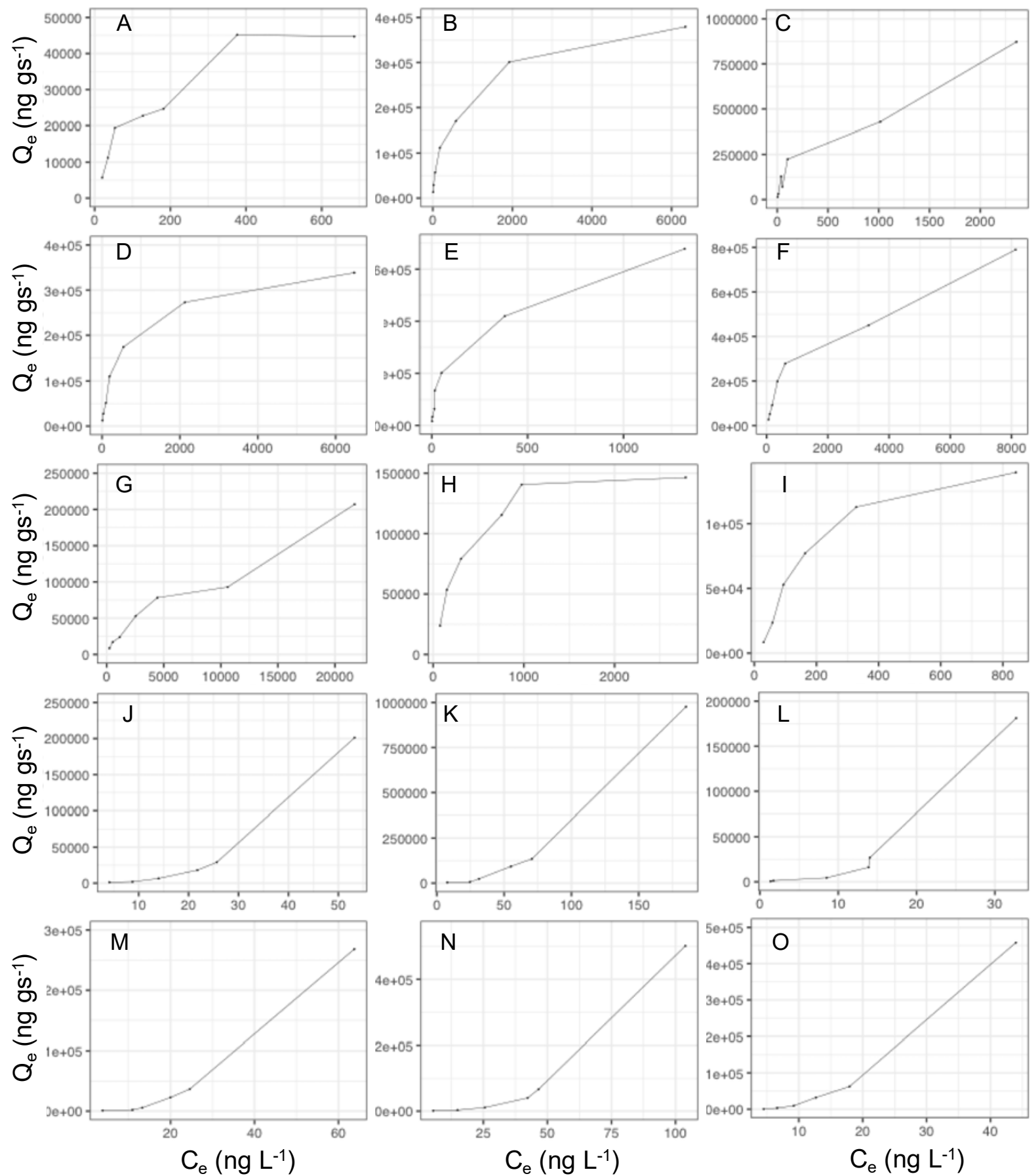

Figure 3. Partitioning isotherms $\left(\mathrm{T}=8^{\circ} \mathrm{C}\right)$ for a set of selected compounds representing the 6

330 different classes, i.e. (alkyl)phenols: isopropylphenol (a), personal care products: methylparaben

331 (b) and DEET (c), pesticides: acetamiprid (d) and diuron (e), pharmaceuticals: bezafibrate (f) and 
sarafloxacine (g), phthalates: monomethyl phthalate (h) and dimethyl phthalate (i), and steroidal

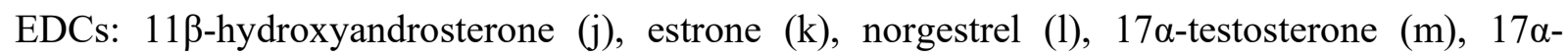
acetoxyprogesterone (n) and $\beta$-zeranol (o).

Do environmental conditions affect $K_{s w}$ ? The dependency of the $K_{s w}$ on environmental conditions was investigated using the Box-Behnken RSM design. Temperature, $\mathrm{pH}$ and salinity each independently significantly $(\mathrm{p}<0.05)$ impacted $\mathrm{K}_{\mathrm{sw}}$ for most of the contaminants. Only for the phthalates and alkylphenols (Tables S 4 and S 5), temperature did not significantly affect $\mathrm{K}_{\mathrm{sw}}$. Overall, the effect of solely temperature on the $\mathrm{K}_{\mathrm{sw}}$ was more significant as compared to $\mathrm{pH}$ and salinity.

To better understand the nature of the partitioning process upon changing temperature, a number of thermodynamic parameters (Figure 4 and Table S 6) were calculated using the van't Hoff equation (Eq. 3) and the change in Gibbs free energy (Eq. 4). For all compounds (at fixed conditions of $\mathrm{pH}$ and salinity), a decrease in $\log \mathrm{K}_{\mathrm{sw}}$-values was observed (difference in $\log \mathrm{K}_{\mathrm{sw}}$ ranged between 0.06 and 5.19), when increasing temperature with $12^{\circ} \mathrm{C}$ (based on environmental range) confirming the exothermic nature $(\Delta \mathrm{H}<0)$ of the partitioning process.

The magnitude of $\Delta \mathrm{H}$ may indicate the nature of the sorption process; i.e. between 0 and $-40 \mathrm{~kJ}$ $\mathrm{mol}^{-1}$ for physisorption, whereas in case of chemisorption (covalent and ionic interactions) $-400 \mathrm{~kJ}$ mol $^{-1}$ will be mostly exceeded ${ }^{46,47}$. It should be noted that there is no sharp boundary between physisorption and chemisorption ${ }^{48}$. The largest negative enthalpies were observed for the steroidal $\operatorname{EDCs}\left(\overline{\Delta H}=-113 \mathrm{~kJ} \mathrm{~mol}^{-1}\right)$, followed by $\overline{\Delta H}_{\text {phthalates }}=-92 \mathrm{~kJ} \mathrm{~mol}^{-1}, \overline{\Delta H}_{\text {alkylphenols }}=-56 \mathrm{~kJ} \mathrm{~mol}^{-}$ ${ }^{1}, \overline{\Delta H}_{\text {personal care products }}=-32 \mathrm{~kJ} \mathrm{~mol}^{-1}, \overline{\Delta H}_{\text {pesticides }}=-25 \mathrm{~kJ} \mathrm{~mol}^{-1}$ and $\overline{\Delta H}_{\text {pharmaceuticals }}=-13$ $\mathrm{kJ} \mathrm{mol}^{-1}$. Physisorption indicates to be the main driver for partitioning of personal care products, 
pesticides, pharmaceuticals and alkylphenols, and is dominated by Van der Waals interactions 356 (weak interactions between compounds and sorbent that are sufficiently close to each other). The 357 largest negative enthalpies were observed for the phthalates and steroidal EDCs. The sorption of 358 phthalates and steroidal EDCs have shown to be driven by stronger interactions to the sorbent, 359 such as hydrogen bonding. It can be presumed that partitioning of phthalates and steroidal EDCs 360 is driven by multiple hydrogen bonding with the sorbent as the enthalpy change of an individual 361 hydrogen bond amounts around $24 \mathrm{~kJ} \mathrm{~mol}^{-1} 49$. For those compounds for which partitioning is 362 mainly dominated by physisorption and lack of strong interactions, the sorption process is more reversible. This could be useful to perform e.g. passive dosing experiments for toxicity testing ${ }^{50}$.
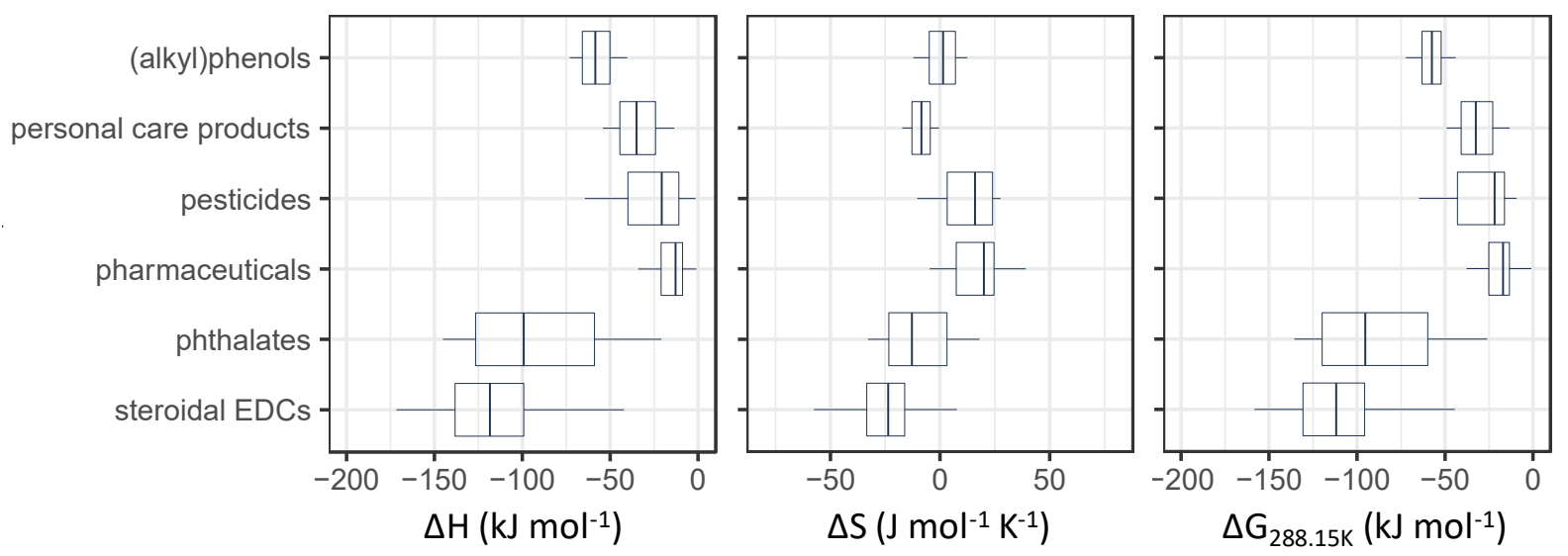

Figure 4. Thermodynamic parameters, i.e. change in enthalpy $(\Delta \mathrm{H})$, change in entropy $(\Delta \mathrm{S})$ and change in free Gibbs energy $(\Delta \mathrm{G})$ during sorption for the alkylphenols, personal care products, pesticides, pharmaceuticals, phthalates and steroidal EDCs.

370 The steroidal EDCs also demonstrated a negative $\Delta \mathrm{S}\left(\overline{\Delta S}_{\text {steroidal } E D C s}=-23 \mathrm{~J} \mathrm{~mol}^{-1} \mathrm{~K}^{-1}\right)$,

371 suggesting no significant alteration of the molecular structure in the sorbed state ${ }^{51,52}$, which 
implies that the sorption process is enthalpy-driven. For the other compound classes, less negative $\Delta \mathrm{H}$ and mainly positive $\Delta \mathrm{S}$ values were observed. Vinmonses et al. (2009) suggested that positive $\Delta \mathrm{S}$ values mark structural changes taking place on the sorbent, and as such increase randomized binding during sorption ${ }^{53}$. The magnitude of the negative $\Delta \mathrm{G} 288.15 \mathrm{~K}$ value indicates the spontaneous nature of the equilibrium sorption process, with higher negative values marking a more spontaneous sorption to reach equilibrium at lower temperatures according to Ahmad and Kumar (2010) and Vimonses et al. (2009). Our negative $\Delta \mathrm{G}_{288.15 \mathrm{~K}}$ data for the steroidal EDCs thus indicate a more rapid, spontaneous and stronger bonding of the latter to the sorbent ${ }^{53-55}$, offering an explanation for their relatively high $\log \mathrm{K}_{\mathrm{sw}}$ as compared to the other compound classes (Figure 2). Predicting the $\log \mathrm{K}_{\mathrm{sw}}$ based on the determined thermodynamic variables also resulted in a lack-of-fit".

With respect to the effect of $\mathrm{pH}$, the $\log \mathrm{K}_{\mathrm{sw}}$ were not significantly ( $\mathrm{p}$-value $>0.05$ ) impacted, except for 11 out of 131 organic contaminants. No general conclusion can however be drawn with relation to the impact of the $\mathrm{pH}$ on compound behaviour for all compound groups as the chemical speciation of organic molecules in water is governed by both the aqueous $\mathrm{pH}$ and the compounds' pKas. Similar results were reported by Stroski et al. (2018), with respect to the effect of $\mathrm{pH}$ on the sorption of 28 out of 31 pesticides and pharmaceuticals ${ }^{56}$. Only for strong cationic (rimantadine and trimethoprim) and strong anionic compounds (i.e. sulfadoxine, sulfamethazine, sulfamethoxazole and clorfibric acid), a pH dependency was noticed. Comparing the partitioning at different $\mathrm{pHs}$ of sorbent and water, it was noted that an increased $\mathrm{pH}$ caused lower (difference in $\log \mathrm{K}_{\mathrm{sw}}$ ranged between 0.24 and 0.82 over $3 \mathrm{pH}$-units) or higher (difference in log $\mathrm{K}_{\mathrm{sw}}$ ranged between 0.14 and 0.22 over $3 \mathrm{pH}$ units) $\mathrm{K}_{\mathrm{sw}}$ for cationic and anionic compounds, respectively. These results are in line with the work of Jeong et al. (2017), which reported that $\mathrm{pH}$ tendancy can 
only be predicted for anionic and cationic compounds. In the current study, however, this was merely observed for strong cationic and anionic compounds, more specifically mecoprop, rimantadine, trimethoprim, venlafaxine, sulfadoxin, sulfamethazine, sulfamethoxazole and clofibric acid.

Different salt concentrations were used to assess the influence of ionic strength on partitioning. Altering the salinity did not impact (within the experimentally observed standard deviations of the RSM) the $\mathrm{K}_{\mathrm{sw}}$ of the steroidal EDCs, phthalates and (alkyl)phenols $(\mathrm{p}>0.05)$. For the personal care products, pesticides and pharmaceuticals, the influence of salinity on the $\mathrm{K}_{\mathrm{sw}}$ was compound specific (difference in $\log \mathrm{K}_{\mathrm{sw}}$ ranged between 0.01 and 1.16 over 35 psu units). These findings agree well with previous work, in which it was demonstrated that the effect of salinity is compound-specific ${ }^{24,57}$. As salinity is known to impact the ionic composition of seawater, it may be anticipated that the sorption process, which is pKa-dependent is affected by the salinity in a compound-specific way. However, no significant relationship between the ionic strength and compound-specific $\log \mathrm{K}_{\mathrm{sw}}$ value of the 131 selected organic contaminants was observed for any of the sub-classes and the complete dataset.

\section{ASSOCIATED CONTENT}

\section{Sorbent and water analysis}

Figures. Figure S1: The particle size distribution of hydrophilic DVB. Figure S2. Schematic overview of the sorbent and water analysis. During step 1 a glass fibre filter was used, in step 2 the most suitable cartridge (red colored) for each group of organic contaminants was used (see specifications in table under the schematic overview). The yellow dots and yellow colored area represent the hydrophilic DVB sorbent that was used in the experiments. Figure S3. The averaged 
NIR spectra ( $n=3$ ) of hydrophilic DVB (blue) and Oasis ${ }^{\text {TM }}$ HLB(red). Figure S4. Chart depicting the effect of type (y-axis) and number of functional groups (color intensity) on $\mathrm{K}_{\mathrm{sw}}$ (x-axis).

Tables. Table S1. Descriptive table of the compounds used in the batch experiments. Group, chemical formula, molecular weight and polarity are presented in the table. Table S2. The average mass balance (\%), standard deviation (SD) and the corresponding analytical repeatability (\% RSDs) of each organic contaminants studied. Table S3. The calculated sorbent-water equilibrium partitioning coefficients ( $\log \mathrm{Ksw}$ ) with their corresponding standard deviations (SD). $\mathrm{n}$ represents the number of datapoints originating from time points after which equilibrium was established. Log P represents the polarity index of the compound. Table S4. The calculated Freundlich coefficients (KF) and exponents (n) with their corresponding standard deviation (SD) and significance ( $\mathrm{p}$-value). The p-value represents the goodness-of-fit through the Freundlich model. The Asterix $(*)$ corresponds to compounds that could not be calculated, because concentrations were detected below detection limits, resulting in in lack-of data points for constructing a Freundlich model. Table S5. The statistical evaluation of the response surface modelling (RSM) encompassing the significance of the interaction terms. The Asterix $(*)$ corresponds to compounds that could not be calculated, because concentrations were detected below detection limits, resulting in in lack-of data points for constructing a reliable Box-Behnken design. $\mathrm{T}, \mathrm{pH}$ and $\mathrm{S}$ corresponds to temperature, acidity and salinity, respectively. Table S6. The coefficients of the obtained response surface models. The Asterix $(*)$ corresponds to compounds that could not be calculated,

437 because concentrations were detected below detection limits, resulting in in lack-of data points for constructing a reliable Box-Behnken design. T, $\mathrm{pH}$ and $\mathrm{S}$ corresponds to temperature, acidity and salinity, respectively. Table S7. The calculated thermodynamic parameters, i.e. change in enthalpy 
441 available data-points during sorption for the calculations). The Asterix(*) corresponds to 442 compounds that could not be calculated, because concentrations were detected below detection 443 limits, resulting in in lack-of data points for constructing a reliable Box-Behnken design.

\section{AUTHOR INFORMATION}

445 Corresponding Author

446 * Tel: +329264 74 75. E-mail: Lynn.Vanhaecke@UGent.be

\section{Author Contributions}

448 The manuscript was written through contributions of all authors. All authors have given approval 449 to the final version of the manuscript. ${ }^{1}$ These first authors contributed equally. ${ }^{2}$ These senior 450 authors contributed equally.

\section{Funding Sources}

452 This work fits within the NewSTHEPS project (BR/143/A2/NEWSTHEPS), supported by the 453 Belgian Science Policy (BELSPO). The contribution of Foppe Smedes was also supported by the 454 RECETOX Research Infrastructure (LM2015051 and CZ.02.1.01/0.0/0.0/16_013/0001761). The 455 financial support from the Hercules Foundation (Flemish Government; AUGE/11/016) and from 456 the Ghent University Special Research Fund (01B07512) is acknowledged for the UHPLC-Q457 ExactiveTM and the automated SPE equipment, respectively.

\section{ACKNOWLEDGMENT}

459 The authors wish to thank prof. dr. Dumoulin Ann, M.Sc. Deprez Dieter and B.Sc.

460 Vandenbussche Laura for their technical contribution to the manuscript. 
DVB, Hydrophilic divinylbenzene; SPE, solid-phase extraction; Ksw, sorbent-water partitioning coefficients; PDMS, polydimethylsiloxane; SDB-RPS, sulfonated divinylbenzene - reversed phase sulfonate; EDCs, endocrine disrupting compounds; RSM, response surface modelling; FTIR, Fourier transform infrared; NIR, Near-infrared; MW, molecular weight; PAHs, polycyclic aromatic hydrocarbons; PCBs, polychlorinated biphenyls.

\section{REFERENCES}

(1) Scheringer, M. Environmental Chemistry and Ecotoxicology: In Greater Demand than Ever. Environmental Sciences Europe. 2017, p 3. https://doi.org/10.1186/s12302-0160101-x.

(2) Andrade-Eiroa, A.; Canle, M.; Leroy-Cancellieri, V.; Cerdà, V. Solid-Phase Extraction of Organic Compounds: A Critical Review (Part I). TrAC - Trends in Analytical Chemistry. Elsevier June 1, 2016, pp 641-654. https://doi.org/10.1016/j.trac.2015.08.015.

(3) Asgarpour Khansary, M.; Shirazian, S.; Asadollahzadeh, M. Polymer-Water Partition Coefficients in Polymeric Passive Samplers. Environ. Sci. Pollut. Res. 2017, 24 (3), 26272631. https://doi.org/10.1007/s11356-016-8029-7.

(4) Thompson, J. M.; Hsieh, C. H.; Luthy, R. G. Modeling Uptake of Hydrophobic Organic Contaminants into Polyethylene Passive Samplers. Environ. Sci. Technol. 2015, 49 (4), 2270-2277. https://doi.org/10.1021/es504442s.

(5) Ahrens, L.; Daneshvar, A.; Lau, A. E.; Kreuger, J. Characterization of Five Passive Sampling Devices for Monitoring of Pesticides in Water. J. Chromatogr. A 2015, 1405, 111. https://doi.org/10.1016/j.chroma.2015.05.044. 
483

484

485

486

487

488

489

490

491

492

493

494

495

496

497

498

499

500

501

502

503

504

(6) Martin, A.; Margoum, C.; Randon, J.; Coquery, M. Silicone Rubber Selection for Passive Sampling of Pesticides in Water. Talanta 2016, 160, 306-313. https://doi.org/10.1016/j.talanta.2016.07.019.

(7) Smedes, F.; Geertsma, R. W.; Van Der Zande, T.; Booij, K. Polymer-Water Partition Coefficients of Hydrophobic Compounds for Passive Sampling: Application of Cosolvent Models for Validation. Environ. Sci. Technol. 2009, 43 (18), 7047-7054. https://doi.org/10.1021/es9009376.

(8) Lissalde, S.; Charriau, A.; Poulier, G.; Mazzella, N.; Buzier, R.; Guibaud, G. Overview of the Chemcatcher ${ }^{\circledR}$ for the Passive Sampling of Various Pollutants in Aquatic Environments Part B: Field Handling and Environmental Applications for the Monitoring of Pollutants and Their Biological Effects. Talanta. Elsevier February 1, 2016, pp 572-582. https://doi.org/10.1016/j.talanta.2015.06.076.

(9) Charriau, A.; Lissalde, S.; Poulier, G.; Mazzella, N.; Buzier, R.; Guibaud, G. Overview of the Chemcatcher ${ }^{\circledR}$ for the Passive Sampling of Various Pollutants in Aquatic Environments Part A: Principles, Calibration, Preparation and Analysis of the Sampler. Talanta 2016, 148, 556-571. https://doi.org/10.1016/J.TALANTA.2015.06.064.

(10) Booij, K.; Chen, S. Review of Atrazine Sampling by Polar Organic Chemical Integrative Samplers and Chemcatcher. Environ. Toxicol. Chem. 2018, 37 (7), 1786-1798. https://doi.org/10.1002/etc.4160.

(11) Alvarez, D. a; Petty, J. D.; Huckins, J. N.; Jones-Lepp, T. L.; Getting, D. T.; Goddard, J. P.; Manahan, S. E. Development of a Passive, in Situ, Integrative Sampler for Hydrophilic Organic Contaminants in Aquatic Environments. Environ. Toxicol. Chem. 2004, 23 (7), 
(12) Metcalfe, C.; Hoque, M. E.; Sultana, T.; Murray, C.; Helm, P.; Kleywegt, S. Monitoring for Contaminants of Emerging Concern in Drinking Water Using POCIS Passive Samplers. Environ. Sci. Process. Impacts 2014, 16 (3), 473. https://doi.org/10.1039/c3em00508a.

(13) Stiles, R.; Yang, I.; Lippincott, R. L.; Murphy, E.; Buckley, B. Measurement of Drinking Water Contaminants by Solid Phase Microextraction Initially Quantified in Source Water Samples by the USGS. Environ. Sci. Technol. 2008, 42 (8), 2976-2981. https://doi.org/10.1021/es071804i.

(14) Kermani, F. R.; Tugulea, A.-M.; Hnatiw, J.; Niri, V. H.; Pawliszyn, J. Application of Automated Solid-Phase Microextraction to Determine Haloacetonitriles, Haloketones, and Chloropicrin in Canadian Drinking Water. Water Qual. Res. J. 2013, 48 (1), 85-98. https://doi.org/10.2166/wqrjc.2013.012.

(15) Grandy, J. J.; Singh, V.; Lashgari, M.; Gauthier, M.; Pawliszyn, J. Development of a Hydrophilic Lipophilic Balanced Thin Film Solid Phase Microextraction Device for Balanced Determination of Volatile Organic Compounds. Anal. Chem. 2018, 90 (23), 14072-14080. https://doi.org/10.1021/acs.analchem.8b04544.

(16) Huysman, S.; Van Meulebroek, L.; Vanryckeghem, F.; Van Langenhove, H.; Demeestere, K.; Vanhaecke, L. Development and Validation of an Ultra-High Performance Liquid Chromatographic High Resolution Q-Orbitrap Mass Spectrometric Method for the Simultaneous Determination of Steroidal Endocrine Disrupting Compounds in Aquatic Matrices. Anal. Chim. Acta 2017, 984. https://doi.org/10.1016/j.aca.2017.07.001. 
(17) Fontanals, N.; Marcé, R. M.; Borrull, F. Overview of the Novel Sorbents Available in SolidPhase Extraction to Improve the Capacity and Selectivity of Analytical Determinations. Contrib. to Sci. 2011, 6 (2), 199-213. https://doi.org/10.2436/20.7010.01.97.

(18) European Commission. Commission Implementing Decision (EU) 2015/495 of 20 March 2015 Establishing a Watch List of Substances for Union-Wide Monitoring in the Field of Water Policy Pursuant to Directive 2008/105/EC of the European Parliament and of the Council; 2015; Vol. 58, pp 40-42. https://doi.org/http://eurlex.europa.eu/pri/en/oj/dat/2003/1_285/1_28520031101en00330037.pdf.

(19) Slobodnik, N. A. NORMAN Position Paper Collection, Exchange and Interpretation of Data on Emerging Substances Towards a Harmonised Approach for Collection and Interpretation of Data on Emerging Substances in Support of European Environmental Policies; 2014.

(20) Ospar. OSPAR Commission https://www.ospar.org/about/publications (accessed Dec 4, 2018).
(21) European
Chemicals
Agency.
Understanding
Reach https://echa.europa.eu/regulations/reach/understandingreach\%5Cnhttp://echa.europa.eu/web/guest/regulations/reach/understanding-reach.

(22) Copeland, C. Clean Water Act: A Summary of the Law. In Atmospheric Deposition of Pollutants and the EPA; 2012. https://doi.org/10.4172/2332-0915.1000133.

(23) International, A. ASTM D-1141-98(2013) Seawater; 2013.

(24) Bayen, S.; Segovia, E.; Loh, L. L.; Burger, D. F.; Eikaas, H. S.; Kelly, B. C. Application of 
Polar Organic Chemical Integrative Sampler (POCIS) to Monitor Emerging Contaminants in Tropical Waters. Sci. Total Environ. 2014, 482-483 (1), 15-22. https://doi.org/10.1016/j.scitotenv.2014.02.082.

(25) MacLeod, S. L.; McClure, E. L.; Wong, C. S. Laboratory Calibration and Field Deployment of the Polar Organic Chemical Integrative Sampler for Pharmaceuticals and Personal Care Products in Wastewater and Surface Water. Environ. Toxicol. Chem. 2007, 26 (12), $2517-$ 2529. https://doi.org/10.1897/07-238.1.

(26) Huysman, S.; Van Meulebroek, L.; Janssens, O.; Vanryckeghem, F.; Van Langenhove, H.; Demeestere, K.; Vanhaecke, L. Targeted Quantification and Untargeted Screening of Alkylphenols, Bisphenol A and Phthalates in Aquatic Matrices Using Ultra-HighPerformance Liquid Chromatography Coupled to Hybrid Q-Orbitrap Mass Spectrometry. Anal. Chim. Acta 2019, 1049, 141-151. https://doi.org/10.1016/j.aca.2018.10.045.

(27) Vanryckeghem, F.; Huysman, S.; Van Langenhove, H.; Vanhaecke, L.; Demeestere, K. Multi-Residue Quantification and Screening of Emerging Organic Micropollutants in the Belgian Part of the North Sea by Use of Speedisk Extraction and Q-Orbitrap HRMS (Submitted). Mar. Pollut. Bull. 2019.

(28) Harman, C.; Allan, I. J.; Vermeirssen, E. L. M. Calibration and Use of the Polar Organic Chemical Integrative Sampler-a Critical Review. Environ. Toxicol. Chem. 2012, 31 (12), 2724-2738. https://doi.org/10.1002/etc.2011.

(29) Tran, H. N.; You, S. J.; Hosseini-Bandegharaei, A.; Chao, H. P. Mistakes and Inconsistencies Regarding Adsorption of Contaminants from Aqueous Solutions: A Critical Review. Water Research. Pergamon September 1, 2017, pp 88-116. 
https://doi.org/10.1016/j.watres.2017.04.014.

570

(30) Kizil, R.; Irudayaraj, J.; Seetharaman, K. Characterization of Irradiated Starches by Using FT-Raman and FTIR Spectroscopy. J. Agric. Food Chem. 2002, 50 (14), 3912-3918. https://doi.org/10.1021/jf011652p.

(31) Guo, X.; Liu, L.; Wu, J.; Fan, J.; Wu, Y. Qualitatively and Quantitatively Characterizing Water Adsorption of a Cellulose Nanofiber Film Using Micro-FTIR Spectroscopy. RSC Adv. 2018, 8 (8), 4214-4220. https://doi.org/10.1039/c7ra09894d.

(32) Mizuguchi, M.; Nara, M.; Kawano, K.; Nitta, K. FT-XR Study of the Ca2+-Binding to Bovine $\alpha$-Lactalbumin. Relationships between the Type of Coordination and Characteristics of the Bands Due to the Asp COO-Groups in the Ca2+-Binding Site. FEBS Lett. 1997, 417 (1), 153-156. https://doi.org/10.1016/S0014-5793(97)01274-X.

(33) Taguchi, Y.; Noguchi, T. Drastic Changes in the Ligand Structure of the Oxygen-Evolving Mn Cluster upon Ca2+ Depletion as Revealed by FTIR Difference Spectroscopy. Biochim. Biophys. Acta - $\quad$ Bioenerg. 2007, $1767 \quad$ (6), 535-540. https://doi.org/10.1016/j.bbabio.2006.11.002.

(34) Davidson, B.; Murray, A. A.; Elfick, A.; Spears, N. Raman Micro-Spectroscopy Can Be Used to Investigate the Developmental Stage of the Mouse Oocyte. PLoS One 2013, 8 (7), e67972. https://doi.org/10.1371/journal.pone.0067972.

(35) Jeong, Y.; Schäffer, A.; Smith, K. Comparison of the Sampling Rates and Partitioning Behaviour of Polar and Non-Polar Contaminants in the Polar Organic Chemical Integrative Sampler and a Monophasic Mixed Polymer Sampler for Application as an Equilibrium 
Passive Sampler. Sci. Total Environ. 2018, 627, 905-915. https://doi.org/10.1016/j.scitotenv.2018.01.273.

592

(36) Jeong, Y.; Schäffer, A.; Smith, K. Equilibrium Partitioning of Organic Compounds to OASIS HLB, as a Function of Compound Concentration, PH, Temperature and Salinity. Chemosphere 2017, 174, 297-305. https://doi.org/10.1016/j.chemosphere.2017.01.116.

(37) O’Connell, S. G.; Kincl, L. D.; Anderson, K. A. Silicone Wristbands as Personal Passive Samplers. Environ. Sci. Technol. 2014, 48 (6), 3327-3335. https://doi.org/10.1021/es405022f.

(38) Lohmann, R. Critical Review of Low-Density Polyethylene's Partitioning and Diffusion Coefficients for Trace Organic Contaminants and Implications for Its Use as a Passive Sampler. Environ. Sci. Technol. 2012, 46 (2), 606-618. https://doi.org/10.1021/es202702y.

(39) Choi, Y.; Cho, Y. M.; Luthy, R. G. Polyethylene-Water Partitioning Coefficients for Parentand Alkylated-Polycyclic Aromatic Hydrocarbons and Polychlorinated Biphenyls. Environ. Sci. Technol. 2013, 47 (13), 6943-6950. https://doi.org/10.1021/es304566v.

(40) Liu, H.; Wei, M.; Yang, X.; Yin, C.; He, X. Development of TLSER Model and QSAR Model for Predicting Partition Coefficients of Hydrophobic Organic Chemicals between Low Density Polyethylene Film and Water. Sci. Total Environ. 2017, 574, 1371-1378. https://doi.org/10.1016/J.SCITOTENV.2016.08.051.

(41) Smedes, F. Silicone-Water Partition Coefficients Determined by Cosolvent Method for Chlorinated Pesticides, Musks, Organo Phosphates, Phthalates and More. Chemosphere 2018, 210, 662-671. https://doi.org/10.1016/j.chemosphere.2018.07.054. 
(42) Ovchinnikov, O. V.; Evtukhova, A. V.; Kondratenko, T. S.; Smirnov, M. S.; Khokhlov, V. Y.; Erina, O. V. Manifestation of Intermolecular Interactions in FTIR Spectra of Methylene Blue Molecules. Vib. Spectrosc. $\quad \mathbf{2 0 1 6}, \quad 86, \quad$ 181-189. https://doi.org/10.1016/J.VIBSPEC.2016.06.016.

(43) Abdelwahab, O.; Amin, N. K. Adsorption of Phenol from Aqueous Solutions by Luffa Cylindrica Fibers: Kinetics, Isotherm and Thermodynamic Studies. Egypt. J. Aquat. Res. 2013, 39 (4), 215-223. https://doi.org/10.1016/j.ejar.2013.12.011.

(44) Ocampo-Perez, R.; Leyva-Ramos, R.; Mendoza-Barron, J.; Guerrero-Coronado, R. M. Adsorption Rate of Phenol from Aqueous Solution onto Organobentonite: Surface Diffusion and Kinetic Models. J. Colloid Interface Sci. 2011, 364 (1), 195-204. https://doi.org/10.1016/j.jcis.2011.08.032.

(45) Lü, G.; Hao, J.; Liu, L.; Ma, H.; Fang, Q.; Wu, L.; Wei, M.; Zhang, Y. The Adsorption of Phenol by Lignite Activated Carbon. Chinese J. Chem. Eng. 2011, 19 (3), 380-385. https://doi.org/10.1016/S1004-9541(09)60224-X.

(46) Ahlert, R. C. Process Dynamics in Environmental Systems. Environ. Prog. 1997, 16 (1), S6-S7. https://doi.org/10.1002/ep.3300160107.

(47) Leuenberger, M. C.; Schibig, M. F.; Nyfeler, P. Gas Adsorption and Desorption Effects on Cylinders and Their Importance for Long-Term Gas Records. Atmos. Meas. Tech. 2015, 8 (12), 5289-5299. https://doi.org/10.5194/amt-8-5289-2015.

(48) Adamson, A. W. Physical Chemistry of Surfaces. J. Electrochem. Soc. 1977, 124 (5), 192C. https://doi.org/10.1149/1.2133374. 
632

633

634

635

636

637

638

639

640

641

642

643

644

645

646

647

648

649

650

651

652

(49) Robin, G. Chemical Fundaments of Geology and Environmental Geoscience; 2015. https://doi.org/10.1017/CBO9781107415324.004.

(50) Vorkamp, K.; McGeer, J. C. How to Improve Exposure Assessment. In Aquatic Ecotoxicology: Advancing Tools for Dealing with Emerging Risks; Academic Press, 2015; pp 77-102. https://doi.org/10.1016/B978-0-12-800949-9.00004-8.

(51) Tejraj, M.; Shivaputrappa, B. Kinetic and Thermodynamic Study on the Sorption of Liquids by Polymer Films: A Simple Laboratory Experiment. 1991, 68 (4), 343-346. https://doi.org/10.1021/ed068p343.

(52) Sujana, M. G.; Pradhan, H. K.; Anand, S. Studies on Sorption of Some Geomaterials for Fluoride Removal from Aqueous Solutions. J. Hazard. Mater. 2009, 161 (1), 120-125. https://doi.org/10.1016/j.jhazmat.2008.03.062.

(53) Vimonses, V.; Lei, S.; Jin, B.; Chow, C. W. K.; Saint, C. Kinetic Study and Equilibrium Isotherm Analysis of Congo Red Adsorption by Clay Materials. Chem. Eng. J. 2009, 148 (2-3), 354-364. https://doi.org/10.1016/j.cej.2008.09.009.

(54) Kebede, S. Groundwater in Ethiopia: Features, Numbers and Opportunities; 2013; Vol. 162. https://doi.org/10.1007/978-3-642-30391-3.

(55) Ahmad, R.; Kumar, R. Adsorptive Removal of Congo Red Dye from Aqueous Solution Using Bael Shell Carbon. Appl. Surf. Sci. 2010, 257 (5), 1628-1633. https://doi.org/10.1016/j.apsusc.2010.08.111.

(56) Stroski, K. M.; Challis, J. K.; Wong, C. S. The Influence of PH on Sampler Uptake for an Improved Configuration of the Organic-Diffusive Gradients in Thin Films Passive Sampler. 

Anal. Chim. Acta 2018, 1018, 45-53. https://doi.org/10.1016/j.aca.2018.02.074.

654 (57) Zhang, Z.; Hibberd, A.; Zhou, J. L. Analysis of Emerging Contaminants in Sewage Effluent 655 and River Water: Comparison between Spot and Passive Sampling. Anal. Chim. Acta 2008,

656 607 (1), 37-44. https://doi.org/10.1016/j.aca.2007.11.024.

657

658 


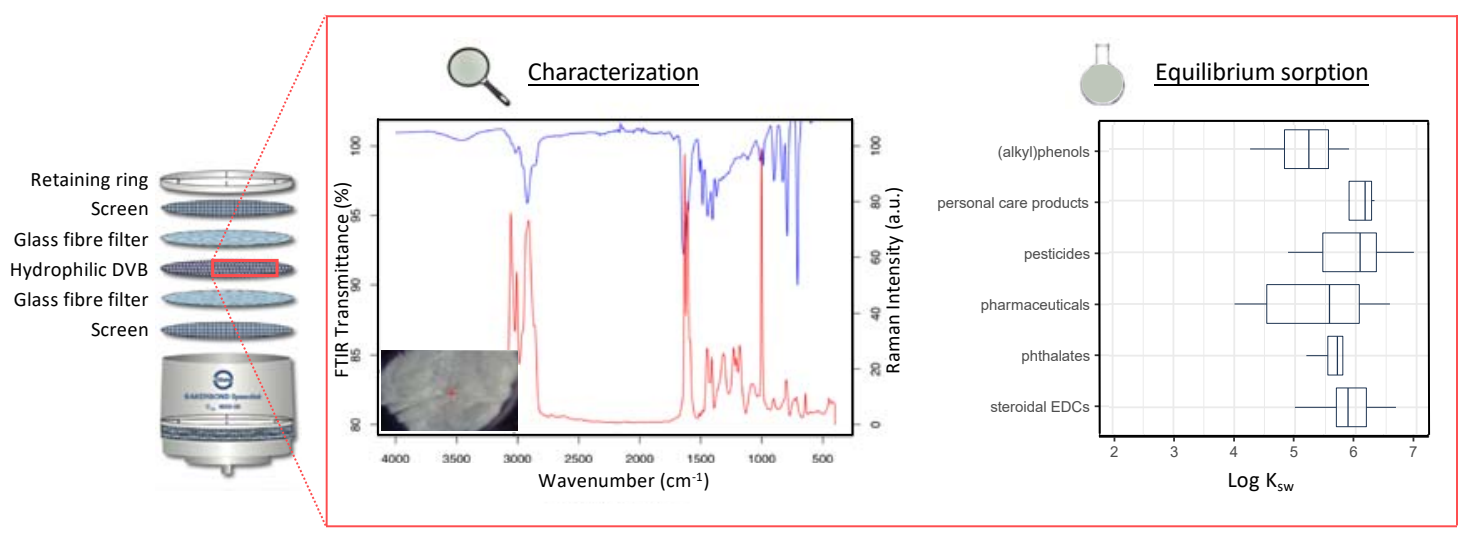

